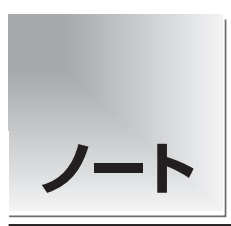

論文受付

2013 年 12 月 24 日

論文受理

2014 年 3 月 24 日

Code No. 331

\section{骨シンチグラフイ診断支援ソフトウェアにおける 空間適応型ノイズ除去処理の有用性}

\section{市川 肇 ${ }^{1} \quad$ 小野口昌久 ${ }^{2} \quad$ 奥田光一 ${ }^{3}$ 加藤豊大 ${ }^{1} \quad$ 寺部充昭 $^{1} \quad$ 島田秀樹 $^{1}$}

\author{
1 豊橋市民病院放射線技術室 \\ 2 金沢大学大学院医学系研究科保健学専攻量子診療技術学分野 \\ 3 金沢医科大学物理学教室
}

\section{緒 言}

日本国内に扔いて骨シンチグラフィ(骨シンチ)は核医 学検査の中で最も施行されている検査である。 そし て，その目的のほとんどが転移性骨腫瘍(骨転移)の診 断であり，一般的には全身像の撮像を行うことによって 全身検索が行われている1)。しかし，診断時において骨 シンチの全身像は, 骨の重なり, 放射性医薬品の投与
量や撮像時間の制限による統計ノイズ，表示ウインドの 調整などがしばしば問題となる。ただし，骨の重なりは 斜位像や single photon emission computed tomography (SPECT)の追加撮像によって解消できる場合が多い2）. また，近年では統計ノイズの大幅な低減効果がある Pixon 法を用いた空間適応型ノイズ除去処理 3 や)ノイズ レベルと分解能の改善を目的に逐次近似の際に

\title{
Usefulness of Spatially Adaptive Noise Reduction Processing in Computer-assisted Diagnosis System for Bone Scintigraphy
}

\author{
Hajime Ichikawa, ${ }^{1 *}$ Masahisa Onoguchi, ${ }^{2}$ Koichi Okuda, ${ }^{3}$ \\ Toyohiro Kato, ${ }^{1}$ Mitsuaki Terabe, ${ }^{1}$ and Hideki Shimada ${ }^{1}$ \\ ${ }^{1}$ Department of Radiology, Toyohashi Municipal Hospital \\ ${ }^{2}$ Department of Quantum Medical Technology, Division of Health Science, Graduate School of Medical Science, Kanazawa \\ University \\ ${ }^{3}$ Department of Physics, Kanazawa Medical University
}

Received December 24, 2013; Revision accepted March 24, 2014

Code No. 331

\section{Summary}

Objectives: The goal of this study was to assess the diagnostic accuracy of Pixon-processed images in comparison with raw images for computer-assisted interpretation of bone scintigraphy (BONENAVI). Methods: Whole-body scans of 57 patients with prostate cancer who had undergone bone scintigraphy for suspected bone metastases were obtained approximately $3 \mathrm{~h}$ after intravenous injection of $740 \mathrm{MBq}{ }^{99 \mathrm{~m}} \mathrm{Tc}-$ methylene diphosphonate. We obtained two image sets: raw images and images processed using the Pixon method. Artificial neural network (ANN) values, bone scan index (BSI), number of hotspots and regional ANN value of two images set were automatically calculated by the BONENAVI software. Areas under the receiver operator characteristic curves (AUC) were calculated in patient-based and lesion-based analyses. Results: In ten cases with bone metastases, ANN, BSI and number of hotspots for processed images were equivalent to those in the raw images. However, in 47 cases without bone metastases, ANN, BSI and number of hotspots for processed images showed significantly lower values than those for the raw images $(p<0.05)$. Sensitivity, specificity and accuracy of the raw images were 90.2, 44.7 and $65.9 \%$, and those of the processed images were 90.2, 57.4 and $72.7 \%$, respectively. The AUC for processed images was equivalent to that for raw images. Conclusions: Specificity and accuracy in the detection of bone metastases showed the Pixon-processed images to have high diagnostic performance. We conclude that the precision of computer-assisted interpretation of bone scintigraphy can be enhanced by using Pixon processing.

Key words: bone scintigraphy, Pixon method, computer-assisted diagnosis (CAD), bone metastases, prostate cancer

*Proceeding author 
Hanning フィルタを用いる方法 ${ }^{4}$ が骨シンチ全身像にも 利用されている。一方，表示ウインドの調整には限界が あるため, 経時的差分画像処理 ${ }^{5)}$ や top-hat 変換処理 ${ }^{6}$ の適応を試みられたが，一般的に臨床利用されていな い.そもそも，骨シンチによる骨転移診断の重要な問題 は，骨シンチ自体が骨転移を間接的に反映しているた め, その特異度は決して高いとは言えず，診断結果は 観察者間の誤差が大きい7)ことである.

このような状況から Sadikらによって骨シンチのため のコンピュータ支援診断ソフトウェアが開発された。こ のシステムは artificial neural networks (ANN)によって 高集積部位の形状，位置，カウントなどの要素から骨 転移の確信度を最小值 0 , 最大值 1 として ANN 值を算 出し, 閾值を 0.5 として骨転移の可能性を評価するもの である ${ }^{8,9)}$ 。さらに，骨転移の広がりの定量指標として Imbriaco らが報告した全身骨量に占める骨転移の割合 をbone scan index(BSI) で定量化が可能となり ${ }^{10)}$,

Sabbatini らの前立腺癌患者での検討では生存期間との 関連が報告されている ${ }^{11)}$ 。これら二つの指標は治療方 針の決定や予後評価などに対して非常に重要であり，

日本版骨シンチ診断支援ソフトウェアBONENAVI では この双方の定量解析が実装され，近年急速に普及して いる. BONENAVIの解析過程は(1)骨格のセグメンテー ション, (2)高集積部位の検出，(3)カウントの正規化，(4) 高集積部位の定量化，5 ANNによる転移の可能性の 分類[局所 ANN 值(regional ANN: rANN 值)の算出],

(6) BSIの算出, (7) ANN 值の算出の順に完全自動処理 される。また，ANNによる転移の可能性の分類は手動 で修正を行うことが可能で，以降の算出結果に影響す る。そして，最終的な結果レポートには rANN 值が 0.5 を超える骨転移の可能性が高い高集積部位は赤色に, 0.5 以下の集積部位が青色に表示される.

このシステムの開発の過程で Horikoshi らは日本人 データベースを構築し, 欧州人データベースよりも優れ たコンピュータ支援診断結果を報告している12)。また，

Kikuchi らは人種間の体格差によるカウント強度の違い が骨格自動セグメンテーションの精度に影響した結果か ら日本人データベースの重要性を報告している13)。これ らの報告から精度よく解析を行うためには，データベー ス画像と試料画像のノイズレベルや高集積部位の形質 が相似している必要があると推測される。一方，このシ ステムのもう一つの利点は観察者が視認しづらい病変

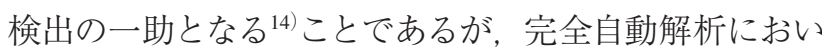
て骨転移の検出を過大評価する傾向にあるとも報告さ れている15).

そこで，骨シンチ診断支援ソフトウェアにおける完全
自動解析での偽陽性検出の改善を目的として, 骨シン チ診断支援ソフトウェアにPixon 法を用いた空間適応 型ノイズ除去処理画像の適応を試みた。本論文では原 画像とノイズ除去処理画像の骨シンチ診断支援ソフト ウェアの解析結果を全身および局所にて比較を行い, 本法の有用性について報告する。

\section{1. 方 法}

\section{1-1 対 象}

2013 年 2 月から 10 月までに前立腺癌の骨転移の評 価を目的に骨シンチを施行し，CT， magnetic resonance imaging (MRI)を含めた画像診断等で骨転移の診断が確 定した 57 例(平均年齢 71.0 歳)で, 内訳は骨転移あり 10 例 (41 病変), 骨転移なし 47 例である。なお, 本検 討で用いたデー夕は当院倫理委員会の確認のもと, 倫 理規定に従って使用した。

\section{1-2 撮像条件および画像処理条件}

${ }^{99 \mathrm{~m}}$ Tc-methylene diphosphonate (MDP) (富士フイルム RI ファーマ社製) $740 \mathrm{MBq}$ を投与して，約 3 時間後に 低エネルギー用高分解能型 (low-energy high resolution: LEHR)コリメータを装着した 2 検出器型ガンマカメラ e.cam (Siemens 社製)を用いて全身像を撮像した。撮像 条件はエネルギーウインド $140 \mathrm{keV} \pm 15 \%$ ，マトリクスサ イズ $1024 \times 256$ ，スキャン速度 $15 \mathrm{~cm} /$ 分とした。

得られた原画像(前面像および後面像)に Siemens 社 製ワークステーション MI application 2007B 搭載の Pixon 法を用いた空間適応型ノイズ除去法である planar processing 処理をデフォルト值 $(\alpha$ ブレンド率； $30 \%$, パ ラメータ；1.7, カーネル半径； 10 , カーネル数; 12 , 繰 り返し；20）にて行い，ノイズ除去処理画像(処理画像) を得た。

なお, Pixon 法は各画素でのスムージングの大きさを 局所カウント值によってノンパラメトリックに調整され る空間適応型のスムージング技術であり, 原画像のカウ ント值を維持しながら, 画像全体のカウントと局所カウ ント情報によって, 分解能を低下させない最適なスムー ジング量を決定するノイズ除去法である3,16).デフォル ト值の $\alpha$ ブレンド率 $30 \%$ では見かけのノイズレベルが 2 倍のカウント数の画像と同等になるとされている.

\section{1-3 コンピュータ支援診断}

骨シンチ診断支援ソフトウェア BONENAVI ver. 1.0 (富士フイルム RI ファーマ社製)を用いて，完全自動 (CADx：バランス)による処理を行い, ANN 值, BSI, ホットスポット数および骨転移の可能性の高低を問わず 
Table 1 Comparison of ANN value, BSI, and number of hotspots for raw and processed images

\begin{tabular}{lccc}
\hline \hline & ANN & BSI & No. of hotspots \\
\hline Bone metastases $(\mathrm{n}=10)$ & & & \\
$\quad$ Raw image & $0.72 \pm 0.30$ & $3.201 \pm 4.015$ & $10.2 \pm 7.7$ \\
$\quad$ Processed image & $0.70 \pm 0.31$ & $3.193 \pm 4.084$ & $9.9 \pm 7.5$ \\
$\quad$ P value & 0.161 & 0.859 & 0.317 \\
No bone metastases $(\mathrm{n}=47)$ & & & \\
$\quad$ Raw image & $0.14 \pm 0.19$ & $0.083 \pm 0.288$ & $1.5 \pm 3.8$ \\
Processed image & $0.12 \pm 0.19$ & $0.070 \pm 0.272$ & $1.0 \pm 2.5$ \\
P value & 0.024 & 0.031 & 0.006 \\
\hline
\end{tabular}

mean \pm standard deviation

検出した高集積部位の rANN 值を算出した。なお，本 論文で記述するホットスポット(数)は BONENAVIで検 出された骨転移の可能性が高い高集積部位であり，一 般的に用いられる視覚的に認める高集積部位とは便宜 的に区別して扱うものとした。

\section{1-4 データ解析および統計解析}

\section{1-4-1 全身での評価}

まず，原画像と処理画像の ANN 值，BSI およびホッ トスポット数の平均値, 回帰直線, 相関係数を骨転移 あり，骨転移なし患者群ごとにそれぞれ算出し，

Wilcoxon paired signed-ranks test によって有意水準 5\% で有意差検定を行った。

つぎに, receiver operator characteristic (ROC) 解析は 原画像と処理画像の ANN 值から ROC-kit (C.E.Metz, シカゴ大学)を使用し, area under the ROC curve(AUC) を比較した。

\section{1-4-2 局所での評価}

放射線科医抢よび泌尿器科医が骨シンチ(原画像掞よ びプラナ像, SPECT も含む), CT, MRI, 血液検査, 臨床所見などによって判定した骨転移の診断結果を ゴールドスタンダードとして, 検出されたホットスポッ トの感度, 特異度および正診率を算出した。有意差検 定は McNemar testによって有意水準 5\%で行った。こ こでの判定は各病変の検出に対して骨転移の可能性が 高いrANN 值が 0.5 を超える高集積部位を骨転移あり として評価した.

また，骨転移の可能性にかかわらず検出した高集積 部位の rANN 值から，全身での評価と同様にROC 解 析を行った.

なお，統計解析には IBM SPSS Statistics ver. 19(IBM 社製)を使用した。

\section{2. 結 果}

\section{2-1 全身での評価}

原画像抢よび処理画像の BONENAVI解析結果の平 均值を Table 1 に, 散布図を Fig. 1 に示す。骨転移を有 する患者群の ANN 值，BSI およびホットスポット数は 原画像と処理画像との間に良好な正の相関を示し, 有 意差を認めなかったが, ANN 值 0.5 以下を示す症例が 原画像と処理画像にそれぞれ 2 例含まれた。一方，骨 転移のない患者群ではすべての解析結果において正の 相関を認めたものの, 原画像に比べ処理画像は低值を 示し, 有意差を認めた $(p<0.05)$. 本来, 骨転移のない 症例であれば，ANN 值は 0.5 以下，BSI とホットスポッ 卜数は 0 を示すところであるが, ANN 值 0.5 を超える 症例が原画像で 4 例, 処理画像で 3 例認め, BSI 㧍よ びホットスポット数は原画像 26 例, 処理画像 20 例で 偽陽性となった。

骨転移がないと診断された患者の解析結果画像の 1 例を Fig. 2 に示す。処理画像ではホットスポットを認め なかったが, 原画像では 3 カ所にホットスポットを検出 した(矢印)。また，骨転移の疑いが低いと検出された集 積にもわずかに差が生じた(矢頭).

Fig. 3 に原画像および処理画像の ANN 值から得られ た ROC 曲線を示す. AUC は原画像 0.937, 処理画像 0.939, $p=0.87$ (two-tailed)で有意差を認めなかった.

\section{2-2 局所での評価}

ホットスポットの自動検出から得た原画像の感度, 特 異度および正診率はそれぞれ 90.2, 44.7, 65.9\%で, 処 理画像では 90.2，57.4，72.7\%であった(Table 2)。感度 に差は認められなかったが, 原画像と比べ処理画像は 特異度が $12.7 \%$, 正診率が $6.8 \%$ 向上し, 有意差を認め た $(p<0.05)$.また，原画像は合計 134 , 処理画像では 110 の偽陽性像が検出された。 

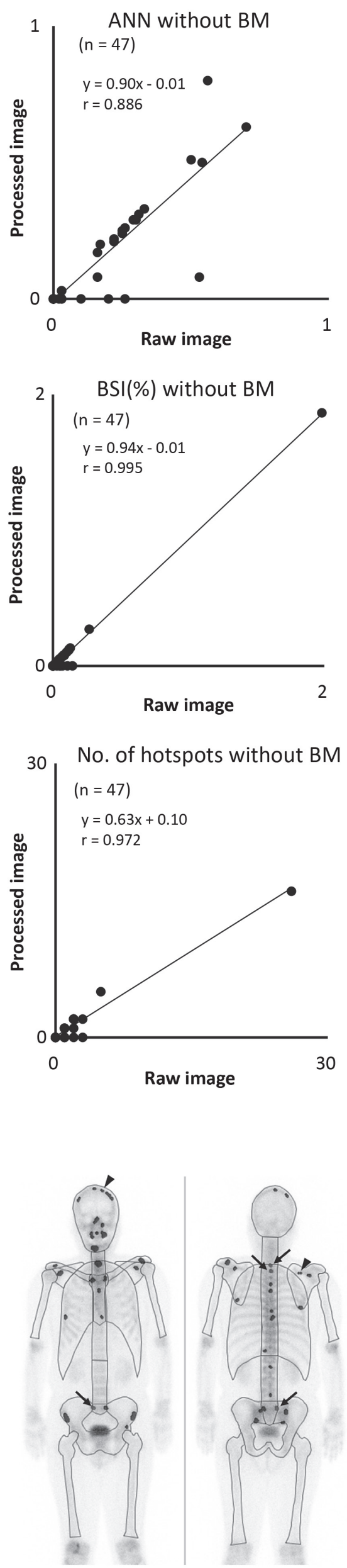
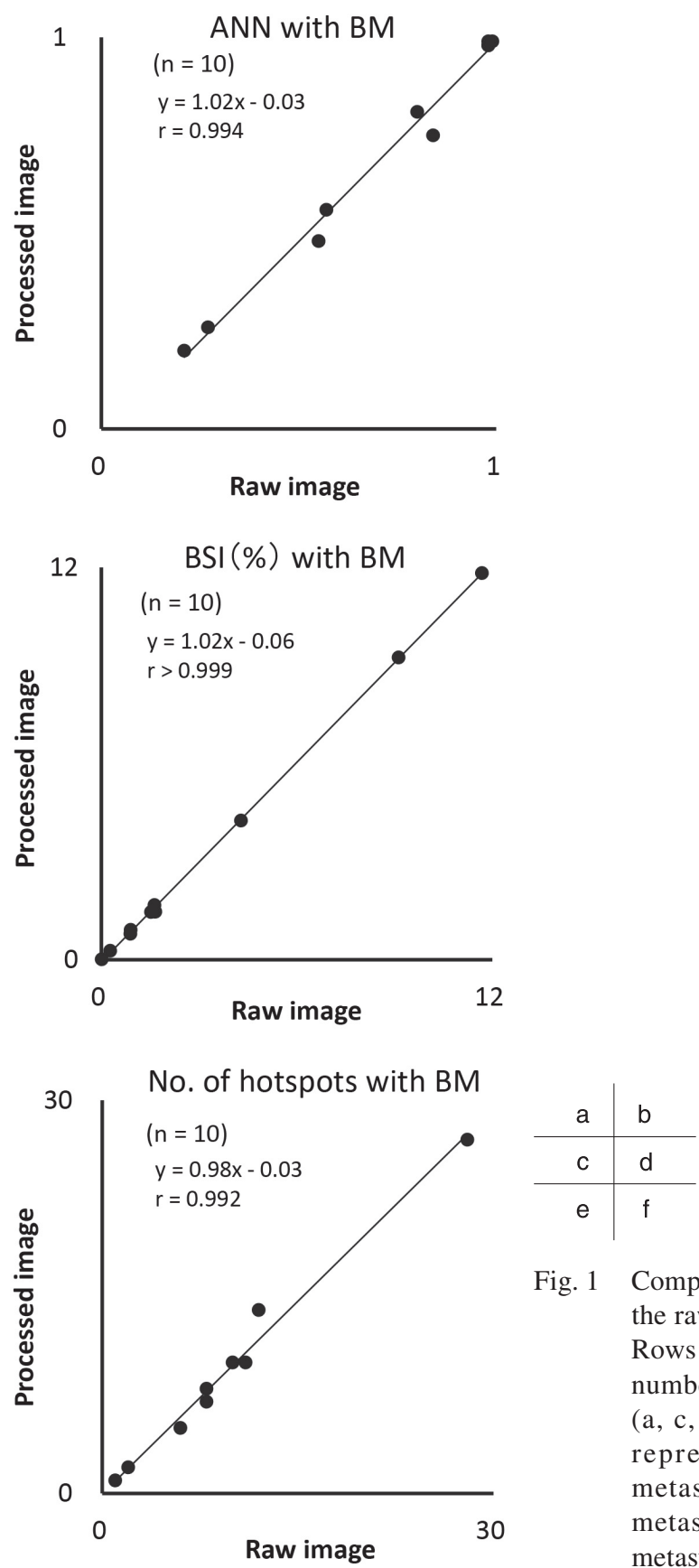

Fig. 1 Comparison of the scoring results for the raw and processed images.

Rows from top to bottom: ANN, BSI, number of hotspots. The left column (a, c, e) and right column (b, d, f) represent 47 cases without bone metastases and 10 cases with bone metastases, respectively. BM: bone metastases.

$\mathrm{a} \mid \mathrm{b}$

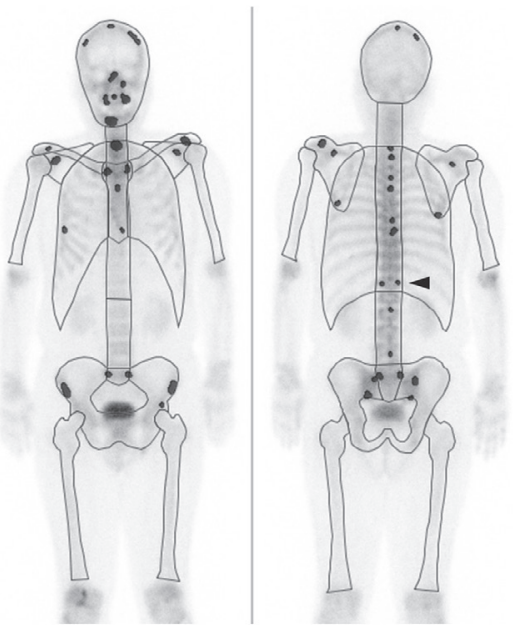

Fig. 2 Study of a 67-year-old male without bone metastases.

(a) Raw image (ANN: 0.10, BSI: 0.144 , number of hotspots: 3 ). (b) Processed image (ANN: 0.00, BSI: 0.000 , number of hotspots: 0 ). Arrows indicate hotspots (false positives). Arrowheads indicate differences in normal or benign uptake patterns. Other high-accumulation areas show normal or benign uptake patterns (e.g., degenerative changes, physiological uptake). 


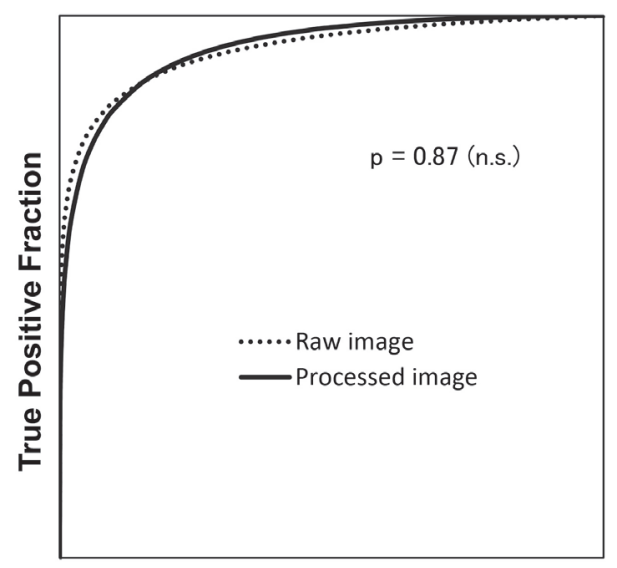

\section{False Positive Fraction}

Fig. 3 Patient-based ROC curves for ANN value for the raw and processed images. Solid curves represent the processed image (AUC: 0.939), and dashed curves represent the raw image (AUC: 0.937$)$. $(\mathrm{n}=57)$ n.s.: not significant

57 症例で検出された高集積部位の合計は 1,388 で, それらの rANN 值から得られた原画像および処理画像 の ROC 曲線を Fig. 4 に示す. AUCは原画像, 処理画 像の順に 0.904, 0.908 であり, $p=0.71$ (two-tailed)で有 意差を認めなかった。

\section{3. 考 察}

全身および局所での評価において処理画像の解析結 果は, 骨転移が存在する集積に対しては原画像と同等 で，正常あるいは良性集積において低值に改善され た。つまり, 処理画像は診断支援ソフトウェアの自動解 析において特異度の改善に寄与する有用な方法である と考えられる。核医学画像の収集カウントは画像診断 分野において決して十分といえるレベルではなく，骨シ ンチ全身像も例外ではない。 そのため, 核医学画像に 対してノイズ除去技術に関する多くの研究が行われて きた3,16〜18).フファントム実験での結果ではあるが, Vija らはPixon 処理によって 16 倍の収集時間で撮像した画 像と同等にノイズレベルを改善できると報告し ${ }^{16)}$, Yahil らはPixon 処理によって特異度を大幅に改善できると報 告している17)。本結果においてもノイズレベルの改善に よって骨転移のない患者群に対してホットスポット検出 の低減に寄与し, ANN 值および BSI の改善につながっ たと考える。

コンピュータ支援診断の性質上，偽陰性をなくすた め安全側に設計せざるを得ないが, 原画像で 134 , 処 理画像で 110 の偽陽性像が検出された。ただ, 57 症例

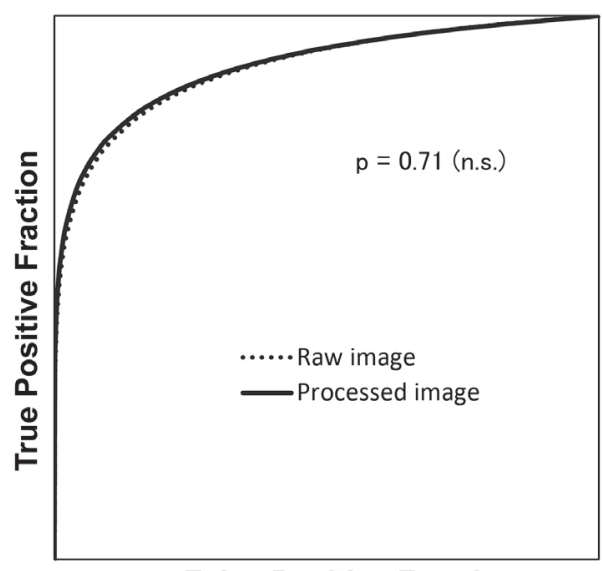

False Positive Fraction

Fig. 4 Lesion-based ROC curves for regional ANN value by raw and processed images.

Solid curves represent the processed image (AUC: 0.908), and dashed curves represent the raw image (AUC: 0.904$).(n=1,388)$; n.s.: not significant

に対して 1,388 の高集積部位を検出したことを考慮する ならば，偽陽性率は10\%未満であるため，それほど高 い偽陽性率ではないとの見解もできる。しかし，より高 い正診率を見込むには，さらなるノイズレベルの改善や 手動によって転移の可能性の分類を修正する必要があ る。まず, より大きなノイズレベルの改善を行うには, planar processing 処理パラメータの $\alpha$ ブレンド率を大き

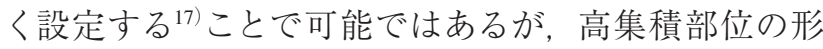
状に影響を及ぼし，偽陰性の増加にもつながりかねな いため, さらなる検討が必要であると考える。また,

TakahashiらはBONENAVI が検出したホットスポット に対して医師による修正を加えることによって完全自動 処理よりも感度, 特異度ともに高值を示すと報告してい る ${ }^{15)}$. このような手法を行うことができる場合において も, 視覚的なコントラストが上昇し, 読影での検出感度 が改善される ${ }^{3,19)}$ 処理画像は有効で, より診断精度の改 善が見达めると推察する. 
造骨性の骨転移として高集積像を来す前立腺癌の骨 転移診断に対して骨シンチ診断支援ソフトウェアの偽 陽性検出の改善を試み，有用な結果が得られた。しか

し，最終的な診断は医師の読影によるものであることは 言うまでもない，また，本検討ではノイズ除去処理パラ メータはメーカ推奨のデフォルト值のみしか用いていな い.このパラメータによっても解析結果は変動すること が予測されるため, 今後, planar processing の処理パラ メー夕に関する詳細な検討を行う必要があると考える。

\section{4. 結 語}

骨シンチ全身像にPixon 法を用いたノイズ除去処理 を行い，骨シンチ診断支援ソフトウェアに扔ける偽陽性 検出の改善を試みた。処理画像では偽陽性が低減し， 特異度および正診率の向上を示す結果が得られた，本 法によって骨シンチ診断支援ソフトウェアに拈ける診断 精度の改善が示唆された。

\section{参考文献}

1) 久田欣一 監, 利波紀久, 久保敦司 編. 2-4-2 骨シンチグラ フィ. 最新臨床核医学 改訂第 3 版。金原出版，東京，1999: 328-333.

2) 遠藤啓吾 監, 小泉 満. 全身骨転移を探る一骨シンチグラ フィー。東京：メディカルチャー, 2000.

3) Wesolowski CA, Yahil A, Puetter RC, et al. Improved lesion detection from spatially adaptive, minimally complex, Pixon reconstruction of planar scintigraphic images. Comput Med Imaging Graph 2005; 29(1): 65-81.

4) 冨口静二. SPECT/CT 時代の新しい 3 次元画像再構成法 (Astonish). MEDIX 2008; 48; 25-30.

5) 河村誠治, 福島重廣, 吉永幸靖, 他. 骨シンチグラフィへ の経時的差分画像法適用に関する研究. 日放技学誌 2005; 61(7): 997-1005.

6）北 章延, 杉本勝也, 土田龍郎, 他. 骨シンチグラフィ全 身プラナー像における Top-hat 変換処理の有用性に関する 検討. 日放技学誌 2013; 69(1): 41-48.

7) Sadik M, Suurkula M, Höglund P, et al. Quality of planar whole-body bone scan interpretations-a nationwide survey. Eur J Nucl Med Mol Imaging 2008; 35(8): 1464-1472.

8) Sadik M, Jakobsson D, Olofsson F, et al. A new computerbased decision-support system for the interpretation of bone scans. Nucl Med Commun 2006; 27(5): 417-423.

9) Sadik M, Hamadeh I, Nordblom P, et al. Computer-assisted interpretation of planar whole-body bone scans. J Nucl Med 2008; 49(12): 1958-1965.

10) Imbriaco M, Larson SM, Yeung HW, et al. A new parameter for measuring metastatic bone involvement by prostate cancer: the Bone Scan Index. Clin Cancer Res 1998; 4(7): 1765-1772.

11) Sabbatini P, Larson SM, Kremer A, et al. Prognostic signif- icance of extent of disease in bone in patients with androgen-independent prostate cancer. J Clin Oncol 1999; 17(3): 948-957.

12) Horikoshi H, Kikuchi A, Onoguchi M, et al. Computeraided diagnosis system for bone scintigrams from Japanese patients: importance of training database. Ann Nucl Med 2012; 26(8): 622-626.

13) Kikuchi A, Onoguchi M, Horikoshi H, et al. Automated segmentation of the skeleton in whole-body bone scans: influence of difference in atlas. Nucl Med Commun 2012; 33(9): 947-953.

14）若林大志, 中嶋憲一. 骨シンチグラフィ診断支援ソフトウェ アの臨床経験. Innervision 2011; 26(9): 107-110.

15) Takahashi Y, Yoshimura M, Suzuki K, et al. Assessment of bone scans in advanced prostate carcinoma using fully automated and semi-automated bone scan index methods. Ann Nucl Med 2012; 26(7): 586-593.

16) Vija AH, Gosnell TR, Yahil A, et al. Statistically based, spatially adaptive noise reduction of planar nuclear studies. Med Imaging, Proceeding SPIE 2005; 5747: 634-645.

17) Yahil A, Vija AH, Hawman EG. Enhanced Feature Extraction in Planar Nuclear Medicine Using Pixon® MinimumComplexity Image Processing. 2006 IEEE Nuclear Science Symposium Conference Record. 2006; 2037-2041.

18）松山江里, 蔡 篤儀, 李 鎔範, 他. 相互情報量による Planar 画像のノイズ低減のための Wavelet 基底関数の選 択. Med Imag Tech 2010; 28(5): 371-380.

19) Lorimer L, Gemmell HG, Sharp PF, et al. Improvement in DMSA imaging using adaptive noise reduction: an ROC analysis. Nucl Med Commun 2012; 33(11): 1212-1216. 